\title{
Reply to Letter Re: Management of Gastric Varices
}

\author{
Bertrand Janne d'Othée - T. Gregory Walker • \\ Arthur C. Waltman • Alan J. Greenfield • \\ Jun Koizumi
}

Published online: 11 August 2011

(C) Springer Science+Business Media, LLC and the Cardiovascular and Interventional Radiological Society of Europe (CIRSE) 2011

We thank Dr. Matsumoto for his comments about our article [1], and we agree that some degree of splenic congestion was present before the BRTO procedure, related not only to the underlying portal hypertension but also to the superimposed splenoportal thrombus. However, splenic congestion was latent in this patient (symptomatically and by imaging) and became overt only after the BRTO procedure. As discussed in the article, we also agree that closing a large gastrorenal shunt may partially increase portal pressure, which may increase blood flow and pressure into other collaterals, thereby worsening esophageal varices and/or ascites. Our discussion advocated the combination of several techniques, including BRTO, transjugular intrahepatic portosystemic shunt (TIPS), and partial splenic embolization (PSE), because each therapy alone often may be insufficient.

B. Janne d'Othée - T. G. Walker · A. C. Waltman

A. J. Greenfield

Department of Radiology, Massachusetts General Hospital,

Harvard Medical School, 55 Fruit Street, GRB-290, Boston,

MA 02114-2696, USA

e-mail: tgwalker@partners.org

A. C. Waltman

e-mail: awaltman@partners.org

A. J. Greenfield

e-mail: agreenfield@partners.org

B. Janne d'Othée $(\square)$

Department of Diagnostic Radiology and Nuclear Medicine, Division of Vascular and Interventional Radiology, University of Maryland School of Medicine, 22 S. Greene Street, Baltimore, MD 21021, USA

e-mail: bjannedothee@umm.edu

\section{J. Koizumi}

Department of Diagnostic Radiology, Tokai University School

of Medicine, Tokyo, Japan

e-mail: jkoizumi@is.icc.u-tokai.ac.jp
Our patient refused to undergo PSE; therefore, this therapy was not an option in this case, although we recognize that a single procedure combining BRTO and PSE could have potentially prevented the worsening of esophageal varices. At the same time, however, it would have decreased antegrade splenic blood flow, which would have reduced the chance of endogenous fibrinolysis of the splenoportal thrombus. The quoted article by Ninoi et al. [2] showed a poor prognosis of patients in classes Child $\mathrm{B}$ and $\mathrm{C}$ compared with Child A, but it did not compare survival rates in Child C patients treated by BRTO versus those untreated. We agree that TIPS creation would probably have been a less beneficial treatment than BRTO and/or PSE, especially in this patient with Child Pugh class C. The problem is that none of these three techniques, and particularly TIPS, yield great results in this patient group. However, our patient was still alive and well at 16 months of follow-up. Due to bowel gas interposition, Doppler ultrasonography could only evaluate the splenic vein near the splenic hilum and demonstrated antegrade flow both before and after BRTO.

Conflict of interest The authors have stated that they have no conflict of interest.

\section{References}

1. Janne d'Othée B, Walker TG, Marota JJ, Waltman AC, Greenfield AJ, Koizumi J (2011) Splenic venous congestion after balloonoccluded retrograde transvenous obliteration of gastric varices. Cardiovasc Intervent Radiol. doi:10.1007/s00270-011-0160-8

2. Ninoi T, Nishida N, Kaminou T, Sakai Y, Kitayama T, Hamuro M, Yamada R, Nakamura K, Arakawa T, Inoue Y (2005) Balloonoccluded retrograde transvenous obliteration of gastric varices with gastrorenal shunt: long-term follow-up in 78 patients. AJR Am J Roentgenol 184(4):1340-1346 